\title{
An Unprotected Distal Left Main Disease Treated with Stenting- A Maiden Experience at a Tertiary Care Center
}

\author{
Nisar A.Tramboo, Iqbal K, Suresh Koul, Vicar Jan, Hilal Rather, Nazir Lone, Kaiser Habib, Ajaz Lone, Manzoor \\ Ali, Neelam Kaul and Asrar Ahmed \\ Department of Medical Cardiology, Sher-i-Kashmir Institute of Medical Sciences, Srinagar
}

\section{ABSTRACT}

Unprotected left main disease which till recently was considered a class III indication for $\mathrm{PCI}$ has been accepted as a IIb indication in the last updated AHA/ACC guidelines. Now world over, UPLM stenting is being increasingly taken up, especially after the entry of drug eluting stents in the coronary interventional arena. The distal left main disease is considered the technically most challenging. We present here a case of distal left main disease with critical ostial LAD and LCX disease, successfully managed with stenting via the double barrel technique. J Med Sci 2010;13(1): 25-27

Key Words: UPLM (unprotected left main), PCI (percutaneous coronary intervention).

\section{Introduction}

There has been a paradigm shift in approach towards treating left main coronary artery disease. In 1970s CABG was found to be better than medical treatment for left main stenosis. ${ }^{1}$ With the advent of the balloon angioplasty era, UPLM treatment with PCI was crippled by poor early outcomes owing to higher rates of dissections, abrupt closures and restenoses, with one year mortality closing to near about $30 \%$. The introduction of bare metal stents were limited by increased rates of repeat revas-cularization mainly because of restenosis, in tune to $20-30 \%$. ${ }^{3}$ The main thrust to UPLM stenting has been given by introduction of drug eluting stents (DES), and now more and more interventionalists world over are approaching this challenging subgroup with a lot more confidence.

\section{Reprint Request:}

Dr. Nisar Ahmad Tramboo

Professor \& Head

Unit-2, Department of Cardiology

SKIMS, P. Box: 27, Srinagar-190011.

\section{Our case: Approach and technique}

Ghulam Mohiuddin (name change), a 65 years old male, smoker, hypertensive was admitted for diagnostic coronary angiography to evaluate CAD. He had angina (CCS III) for over 4 months, a strongly positive TMT (Bruce protocol) with global ST depression and a hypotensive response, indicating multivessel or left main disease on exercise testing. His CAG revealed $90 \%$ ostial LAD disease, $80 \%$ ostial LCX accompanied by $70 \%$ distal left main stenosis (Fig. 1). He had a SYNTAX score of 36 and Euro score of less than 6 and was thus offered CABGS as a treatment strategy, which he denied. So he was taken up for UPLM stenting. His echocardio-graphy demonstrated normal LV functions without RWMA (LVEF $65 \%$ ) and had a normal biochemical profile.

We planned the patient after prior discussions and deliberations in the department. On the day of intervention patient was preloaded with $300 \mathrm{mg}$ of soluble aspirin , $600 \mathrm{mg}$ of clopidogrel and $80 \mathrm{mg}$ of atorvastatin 4 hours before the procedure. Inside the cath lab emergency cart was activated , anaesthetists and cardiac surgeons were informed and IABP (Intra aortic balloon pump) was put in the stand by mode. The 


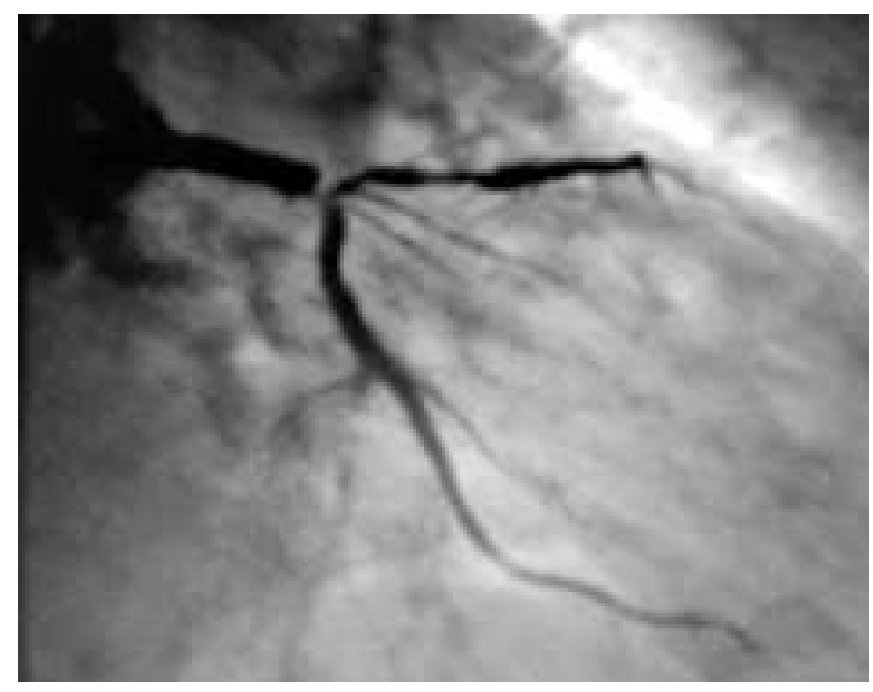

Figure 1: Distal left main, ostial LAD and LCX disease as seen in RAO caudal view

left main was hooked with a 7F EBU 3.5 guiding catheter and both the LAD and LCX vessels were wired with the 0.014" $\mathrm{BMW}$ guidewires. Predilatation of the LAD lesion was done with a $2 \times 10 \mathrm{~mm}$ Firestar (Cordis) balloon@10 atms. Another $2 \times 12 \mathrm{~mm}$ balloon was used for the LCX. A kissing balloon inflation was carried out at $10 \mathrm{atms}$ and no complications were encountered. At this moment,anSKS (simultaneous kissing stent strategy) was planned. Two CYPHER $3 \times 15$ and $2.75 \times 13 \mathrm{~mm}$ stents were deployed simultaneously in the LAD and LCX respectively with a 3-4 $\mathrm{mm}$ overhang in the left main (double barrel technique) @ 8 atms. Then individually, each stent was inflated to a final pressure of 20 atms. Finally another kissing balloon inflation was done at 14 atms. The procedure was successful (Fig. 2) and patient was sent home after 48 hours.

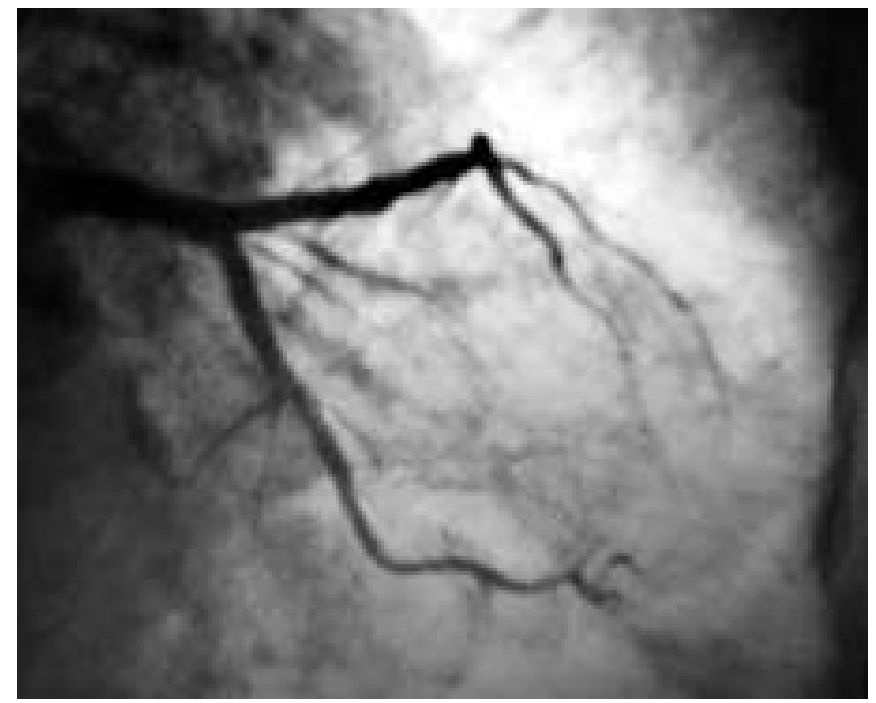

Figure 2: Distal left main stenting via the SKS strategy as seen in RAO caudal view

\section{Discussion}

The treatment of UPLM disease has come a long way. Protected left main implies that it is protected by at least one patent bypass graft to the left anterior descending or left circumflex artery. The last updated AHA/ACC guidelines which were published in November 2009 describe PCI of left main as a class IIb indication. ${ }^{4}$ Left main disease can be ostial, midshaft or distal and the latter is the most challenging to treat via PCI. Coronary interventionalists have now started taking up this difficult coronary subset in increasing numbers. Amongst the most straightforward UPLM lesions, are the midshaft ones and are associated with excellent outcomes on stenting. A recent multicenter registry of 147 patients undergoing UPLM stenting of ostial/ midshaft lesions with sirolimus eluting stents(SES $n=107$ ) or paclitaxel eluting stents ( PES $n=40$ ), found excellent results at midterm follow up. ${ }^{5}$ Mortality in this study was affected by Euroscore. A score of less than 6 had a $0 \%$ mortality but it increased to $6.7 \%$ with higher scores. ${ }^{6}$ Results from some more trials are awaited.

In contrast to the above observations, patients with distal bifurcation disease are more challenging to treat and have less favourable long term outcomes. In a small 50 patient registry, the major area of concern was a high $38 \%$ rate of repeat revascularization. ${ }^{7}$ Some UPLM registries have reported a higher incidence of restenosis at LCX ostium. The cause of this restenosis predilection has been attributed to a sharp bend taken by the LCX, resulting in poor apposition at this site. ${ }^{8}$

IVUS (Intravascular ultrasound ) is commonly used for assessing Left main disease. One commonly used IVUS threshold ${ }^{9,10}$ for significant LM disease is a minimal luminal area of less than $6 \mathrm{~mm}^{2}$ and another being 7.5 $\mathrm{mm}^{2}$. From the available registry data it seems that restenosis and repeat revascularization rates are lower when only one stent is used. ${ }^{11}$ So if the risk of closure of the side branch is low, the current favoured strategy is the provisional approach of stenting the side branch. Two stents should be deployed in the left main only when the operator feels that there is a high probability of closure of the side branch. Various techniques used are the double barrel, T-stenting, Crush and the TAP stenting which is a modified T stenting with intentional protrusion of the side branch stent into the main vessel. A final kissing balloon inflation of both stents should be done at high (e" 16 atms) pressure. ${ }^{8}$ Surveillance angiography at 3 to 6 months which was previously recommended for all left main interventions (Class I AHA/ ACC) is now considered a Class III indication, that is it's no more recommended. ${ }^{4}$

\section{Conclusion}

Unprotected left main stenting is gaining widespread acceptance world over. Through this c 
intend to highlight the importance of a proper preplanning, reviewing evidence and technical strategies, pre-empting complications and good teamwork in order to achieve a successful result in as complex a procedure as distal left main disease.

\section{References}

1. Chaitman BR, Fisher LD, Bourassa MG, et al. Effect of coronary bypass surgery on survival patterns in subsets of patients with left maincoronaryartery $\mathrm{d}$ isease. Report of the Collaborative Study in Coronary Artery Surgery (CASS). Am F Cardiol 1981;48:765-7.

2. O'Keefe JH Jr., Hartzler GO, Rutherford BD, et al. Left main coronary angioplasty: early and late results of 127 acute and elective procedures. Am F Cardiol 1989;64:144-7.

3. Tan WA, Tamai H, Park SJ, et al. Long-term clinical outcomes after unprotected left main trunk per-cutaneous revascularization in 279 patients. Circulation 2001;104: 1609-14.

4. Frederick G. Kushner, Mary Hand, Sidney C et al. 2009 Focused Updates: ACC/AHA Guidelines for the Management of Patients With ST-Elevation Myocardial Infarction (Updating the 2004 Guideline and 2007 Focused Update) and ACC/AHA/SCAI Guidelines on Percutaneous Coronary Intervention (Updating the2005 Guideline and 2007 Focused Update). F Am Coll Cardiol 2009;10:015.
5. Chieffo A, Park SJ, Valgimigli M et al. Favorable long-term outcome after drug-eluting stent implantation in nonbifurcation lesions that involve unprotected left main coronary artery: a multicenter registry. Circulation 2007; 116:158-62.

6. Nashef SA, Roques F, Michel P, et al. European system for cardiac operative risk evaluation (EuroSCORE). Eur $\mathcal{f}$ Cardiothorac Surg 1999;16:9-13.

7. Price MJ, Cristea E, Sawhney N, et al. Serial angio-graphic follow-up of sirolimus-eluting stents for unprotected left main coronary artery revascularization. $\mathcal{F}$ Am Coll Cardiol 2006;47:871-7.

8. Paul S. Teirstein. Unprotected Left Main Intervention. Patient Selection, Operator Technique, and Clinical Outcomes. FACC Interventions 2008;1 (1): 5-13

9. Sano K, Mintz GS, Carlier SG, et al. Assessing intermediate left main coronary lesions using intravascular ultrasound. Am Heart F 2007;154:983-8.

10. Fassa AA, Wagatsuma K, Higano ST, et al. Intravascular ultrasound guided treatment for angiographically indeterminate left main coronary artery disease: a longterm follow-up study. F Am Coll Cardiol 2005;45:204-11.

11. Biondi-Zoccai GGL, Lotrionte M, Moretti C, et al. A collaborativesystematic review and meta-analysis on 1278 patients undergoing percutaneous drug-eluting stenting for unprotected left main coronary artery disease. Am Heart f 2008;155:274-83. 